\title{
REGIME DAS INCAPACIDADES E SUAS PRINCIPAIS MUDANÇAS
}

\section{DISABILITIES SCHEME AND THE MAIN CHANGES}

\author{
Guilherme Calmon Nogueira da Gama* \\ Bruno Lima do Amaral Roale
}

Resumo: Busca-se fazer, neste artigo, uma análise do tema da capacidade de fato e da pessoa incapaz desde o início de vigência do Código Civil de 1916 até os dias atuais, em razão da vigência do Estatuto da Pessoa com Deficiência que, inclusive, modificou significativamente o regime contemporâneo das incapacidades. Deve-se analisar e compreender o novo modelo do regime das incapacidades no Direito Civil brasileiro que se associa e se fundamenta no valor e princípio fundamental do ordenamento jurídico brasileiro, a saber, a dignidade da pessoa humana, aí também compreendida a pessoa com deficiência.

Palavras-chave: Regime das incapacidades. Estatuto da Pessoa com Deficiência. Princípio da Dignidade da Pessoa Humana.

Abstract: This article seeks to analyze the issue of de facto capacity and the incapable person from the beginning of the Civil Code of 1916 until the present day, due to the validity of the Statute of the Disabled People, which even amended significantly the contemporary disability regime. It is necessary to analyze and understand the new model of the disability regime in Brazilian Civil Law that is associated and based on the value and fundamental principle of the Brazilian legal system, namely, the dignity of the human person, including the person with disabilities.

Keywords: Disability scheme. Statute of Persons with Disabilities. Principle of Human Dignity.

\footnotetext{
* Doutor, mestre e graduado em Direito pela Universidade do Estado do Rio de Janeiro (UERJ). Atualmente, é Professor titular de Direito Civil da Universidade do Estado do Rio de Janeiro (graduação e pós-graduação), Professor permanente da Universidade Estácio de Sá e Professor da Faculdade de Direito do IBMEC.

** Graduando em Direito pelo Instituto Brasileiro de Mercado de Capitais (IBMEC).
} 


\section{NOTAS INTRODUTÓRIAS}

O Direito objetiva, em sua essência, regular a vida das pessoas usando de normas justas visando ao bom convívio social. Para tanto usa de diversos princípios para concretizar sua busca ao ponto ideal de controle e justiça social.

Nesse sentido, tanto o Direito Privado quanto o Direito Público são norteados pelo princípio da dignidade da pessoa humana. A ascensão deste ocorreu após o término da Segunda Guerra Mundial, em reação às atrocidades cometidas pelo nazifascismo. Desse modo, a Declaração Universal dos Direito Humanos, proclamada pelas Nações Unidas em 1948, enunciava em seu art. 10: "Todas as pessoas nascem livres e iguais em dignidade e direitos". Essa ideia repercutiu no Brasil com o advento da Constituição Federal de 1988, após mais de duas décadas de ditadura sob o regime militar. Com isso, esse princípio, como observa Maria Celina Bodin de Moraes, "tornou-se um comando jurídico no Brasil" (BODIN DE MORAES, 2010, p. 82), onde é explicitado na forma do artigo 10, III, da Lei Maior como um dos "fundamentos da República". ${ }^{1}$

Sob essa perspectiva, hoje, constata-se que o princípio da dignidade da pessoa humana compreende três aspectos: 1 - respeito à integridade física e psíquica das pessoas; 2- consideração pelos pressupostos materiais mínimos para o exercício da vida; e 3- respeito pelas condições mínimas de liberdade e convivência social igualitária. O legislador, mediante esses pressupostos, optou tutelar por meio de normas jurídicas os grupos considerados vulneráveis como, por exemplo, as pessoas com deficiência. Ademais, esse princípio tem o intuito de individualizar cada um, a fim de garantir a sua total participação na sociedade através do exercício dos seus direitos. Logo, tais aspectos são vistos, também, no âmbito civil, na forma do artigo 10 do Código Civil (BRASIL, 2002): "toda pessoa é capaz de direitos e deveres na ordem civil".

\footnotetext{
${ }^{1}$ Art. 10 A República Federativa do Brasil, formada pela união indissolúvel dos Estados e Municípios e do Distrito Federal, constitui-se em Estado Democrático de Direito e tem como fundamentos:

III - a dignidade da pessoa humana. (BRASIL, 1988).
} 
Sem embargo, observam-se nos artigos $3^{\circ 2}$ e $4^{\circ 3}$ do Código Civil de 2002 causas para limitações ao exercício destes direitos. Tais limitações foram estabelecidas a partir da premissa deque essas pessoas não são consideradas aptas a realizarem plenamente os atos da vida civil.

Ao longo dos anos a concepção de pessoas consideradas incapazes trazida no Código Civil de 1916 (BRASIL, 1916) foi sendo mitigada. Como início da vigência do Código Civil de 2002, por exemplo, determinados artigos, especialmente os que se referem ao regime da capacidade, foram alterados em razão da constitucionalização do Direito Civil, calcadas nas normas sobre Direito Humanos e Direitos Fundamentais (este marco axiológico encontrava-se na fase embrionária). Entretanto, com o advento do Estatuto da Pessoa com Deficiência (EPD) (BRASIL, 2015a) houve, assim, uma forte aproximação da ordem legal aos princípios constitucionais, principalmente, o da dignidade da pessoa humana e o da igualdade material em relação ao Direito Civil. Torna-se possível, dessa forma, a revogação e a alteração de determinadas normas do atual Código Civil que tinham, em sua literalidade e essência, um cunho pejorativo e discriminatório.

Portanto, busca-se fazer, neste artigo, uma análise do tema da capacidade de fato e da pessoa incapaz desde o início de vigência do Código Civil de 1916 até os dias atuais, em razão da vigência do EPD que, inclusive, modificou significativamente o regime contemporâneo das incapacidades.

\section{REGIME DAS INCAPACIDADES SOB A ÉGIDE DO CÓDIGO CIVIL DE 1916}

Pessoa natural é o ser humano como sujeito de direitos e deveres. A ideia obedece a três princípios fundamentais: 1- todo ser humano é pessoa, pelo simples fato de existir e, por isso, é capaz de direitos e deveres na ordem civil; 2- todos têm a mesma personalidade porque todos têm a mesma aptidão para a titularidade de relações jurídicas; e 3- a personalidade é irrenunciável. Ou seja, em palavras mais sucintas apregoa Pierangelo Catalano (1990, p. 47): "todo ser humano é pessoa pelo fato de nascer ou até de ser concebido. Pessoa é o ser humano como sujeito de

${ }^{2}$ Art. $3^{\circ}$ São absolutamente incapazes de exercer pessoalmente os atos da vida civil os menores de 16 (dezesseis) anos. (BRASIL, 2002).

${ }^{3}$ Art. $4^{\circ}$ São incapazes, relativamente a certos atos ou à maneira de os exercer: [...]. (BRASIL, 2002). 
direitos". Conclua-se, portanto, que toda pessoa, ao nascer com vida, é titular de direito e deveres, visto que não há sujeitos sem direitos, como não há direitos sem titular (MOTA PINTO, 2005, p. 196; CASTRO MENDES, 1979).

Com fulcro nessa concepção, agrega-se o instituto da capacidade, uma vez que o mesmo é conexo ao instituto da personalidade; porém, não são palavras sinônimas. Em outras palavras:

Parece-nos, entretanto, que é mister distingui-las. Com efeito, enquanto personalidade jurídica é conceito absoluto (ela existe, ou não existe), capacidade jurídica é conceito relativo (pode ter-se mais capacidade jurídica, ou menos). A personalidade jurídica é a potencialidade de adquirir direitos ou de contrair obrigações; a capacidade jurídica é o limite dessa potencialidade. (BARBERO, 1950, p. 139).

Nessa perspectiva, capacidade e personalidade não são termos sinônimos, visto que pode existir personalidade sem capacidade, como se verifica com o nascituro, que ainda não tem capacidade, e com os falecidos, que já a perderam. Em outras palavras, observa Caio Mário da Silva Pereira (2018, p. 221): "Personalidade e capacidade completam-se: de nada valeria a personalidade sem a capacidade jurídica que se ajusta assim ao conteúdo da personalidade".

Nesse aspecto, o Código Civil de 1916 já presumia a figura do incapaz na forma dos artigos $5^{\circ 4}$ e $6^{\circ 5}$ do seu texto, classificando-a em dois grupos: os absolutamente incapazes e os relativamente incapazes. No primeiro, a pessoa ficava impedida de exercer, por si mesma, qualquer ato da vida jurídica, sendo determinada pela lei civil o suprimento dessa incapacidade pelo antigo pátrio poder, pela tutela ou curatela. Enquanto, no segundo, permitia que o incapaz praticasse determinados atos da vida civil, desde que fosse assistido, ressalvando a prática de outros sem necessidade de assistência.

Além disso, na vigência do Código de 1916 já se impunha a dissociação entre as capacidades de gozo (também denominada capacidade de direito ou de aquisição)

\footnotetext{
${ }^{4}$ Art. $5^{0}$ São absolutamente incapazes de exercer pessoalmente os atos da vida civil: I - os menores de 16 (dezesseis) anos; II - os loucos de todo o gênero; III - os surdos-mudos, que não puderem exprimir a sua vontade IV - os ausentes, declarados tais por ato do juiz. (BRASIL, 1916).

5Art. $6^{\circ}$ São incapazes, relativamente a certos atos (art. 147, I), ou à maneira de os exercer: I - os maiores de 16 (dezesseis) e os menores de 21 (vinte e um) anos (arts. 154 a 156); II - os pródigos; III - os silvícolas. Parágrafo único. Os silvícolas ficarão sujeitos ao regime tutelar, estabelecido em leis e regulamentos especiais, o qual cessará à medida que se forem adaptando à civilização do País. (BRASIL, 1916).
} 
e de exercício (ou capacidade de fato). A primeira versa sobre aptidão para alguém ser titular de direitos e deveres, ser sujeito de relações jurídicas, ou seja, ao nascer com vida a pessoa adquire o conjunto de direitos que Ihe são próprios como, por exemplo, os direitos da personalidade. Assim, como observa Washington de Barros Monteiro (2003, p. 61): "essa espécie de capacidade é reconhecida a todo ser humano, sem qualquer distinção". Enquanto na segunda,- capacidade de agir ou capacidade de fato -, há a aptidão para a prática dos atos da vida civil, e para o exercício dos direitos como efeito imediato da autonomia que as pessoas têm. A capacidade de exercício depende da capacidade natural de entendimento, inteligência da pessoa. Dessa forma, ainda pela conjuntura da época da vigência do Código Civil de 1916 as pessoas com deficiência tinham sua capacidade de exercício limitada pelo legislador, com a presunção de que essas pessoas, por não possuírem um nível razoável de discernimento, não podiam praticar os atos da vida civil, como por exemplo, a compra de um imóvel.

Após essa consideração inicial, é pertinente observar no Código Civil de 1916 que os absolutamente incapazes se enquadravam em uma das três situações: a idade, a enfermidade ou a deficiência mental e a ausência de discernimento (GAMA, 2006, p. 18-20). Na primeira situação, evidenciava-se o arbítrio utilizado pelo legislador com o intuito de garantir um mínimo desenvolvimento de faculdade intelectual e promover a segurança jurídica. Na segunda situação, observava-se que o legislador optou por um conceito subjetivo calcado na ausência do necessário discernimento para os atos da vida civil, compreensiva de todos os casos de insanidade mental, permanente e duradoura, gerando, dessa forma, uma polêmica lexical dentro da doutrina brasileira. Tal se explica eis que há divergências tanto na Ciência Jurídica quanto na Ciência Médica, em razão da imensa diversidade dos níveis dos estados patológicos e a variada de sua extensão nas qualidades psíquicas do enfermo. Ou seja, há certas enfermidades que são mais facilmente perceptíveis como, por exemplo, a esquizofrenia, enquanto outras necessitam de um diagnóstico de um especialista.

Nesse aspecto, esse diploma normativo era vinculado, de forma hegemônica, ao modelo médico ou "modelo reparador" de deficiência, o qual encarava a deficiência como condição patológica, de natureza individual. Isto é, esse modelo 
trazia a ideia de que o problema estava na pessoa com deficiência e que a mesma precisaria ser "curada" I" reparada", para que pudesse ser "normalizada" e voltasse a integralizar a sociedade, desde que conseguisse assemelhar-se às demais pessoas capazes, o máximo possível. Nesse sentido, percebe-se a influência desse modelo, por exemplo, no art. $5^{0^{6}}$ do Código Civil de 1916 , o qual considerava absolutamente incapaz o louco de todo gênero e os surdos-mudos que não pudessem manifestar sua vontade. Desse modo, observa-se a estigmatização feita pelo legislador ao classificar essas pessoas como totalmente incapazes devido à uma patologia, submetendo-as, portanto, à exclusão social. Assim, sob esse aspecto, observam Marcelo Medeiros e Débora Diniz: "O modelo médico identifica a pessoa deficiente como alguém com algum tipo de inadequação para a sociedade." (MEDEIROS; DINIZ, 2004, p. 8).

O modelo médico foi mitigado e nos fins da década de1970, no Reino Unido e nos Estados Unidos, surge o modelo médico-social, o qual tinha como bandeira a "desmedicalização" e a "desinstitucionalização", isto quer dizer, na primeira, o fim do "modelo reparador" com o surgimento de uma nova tendência, ao considerar que a deficiência estava na sociedade e não na pessoa com deficiência; e, na segunda, opunha-se a ideia desse grupo ser considerado como "cidadãos de segunda classe". Outrossim, tinha como escopo a distinção entre lesão e deficiência. A primeira é objeto de discussão sobre saúde, enquanto a segunda é uma questão da ordem dos direitos e da justiça social e, portanto, essencialmente normativa. Ou seja, com o surgimento desse modelo, a deficiência que, outrora, era considerada fator de exclusão social, agora, torna-se fator de inclusão e integração, visto que a mesma é uma característica inerente à pessoa como, por exemplo, o sexo, a cor da pele.

Assim, como observam Medeiros e Diniz (2004, p. 8): "o modelo social, por sua vez, inverte o argumento e identifica a deficiência na inadequação da sociedade para incluir todos, sem exceção". Ademais, esse modelo social permitiu a aproximação do Código Civil aos Direitos Humanos e a defesa da dignidade da pessoa humana como valor a ser alcançado, visto que o modelo médico tinha, como

\footnotetext{
${ }^{6}$ Art. $5^{0}$ São absolutamente incapazes de exercer pessoalmente os atos da vida civil: I - os menores de 16 (dezesseis) anos; II - os loucos de todo o gênero; III - os surdos-mudos, que não puderem exprimir a sua vontade IV - os ausentes, declarados tais por ato do juiz (BRASIL, 1916).
} 
principal escopo, atribuir a responsabilidade pela deficiência e pela impossibilidade de equalização à pessoa que a detivesse. Sob essa perspectiva, apregoam:

É de que a deficiência não deve ser entendida como um problema individual, mas como uma questão eminentemente social, transferindo a responsabilidade pelas desvantagens dos deficientes das limitações corporais do indivíduo para a incapacidade da sociedade de prever e ajustarse à diversidade. (MEDEIROS; DINIZ, 2004, p. 8).

Sob tal enfoque, no Código Civil de 2002 essa associação foi minimizada pela referência ao discernimento, mas ainda assim houve menção expressa a que uma deficiência leva a déficit cognitivo, sendo sujeita à uma declaração judicial acerca da incapacidade. Portanto, evidencia-se um conflito entre o regime jurídico das incapacidades e a dignidade da pessoa humana, valor esse fundamental do ordenamento jurídico, como é salientado por Rafael Garcia Rodrigues (2003, p. 2425): "É necessário, por conseguinte, repensar o regime das incapacidades, especialmente, quando estiver em jogo situações jurídicas existenciais envolvendo o próprio desenvolvimento humano do indivíduo".

Outro aspecto importante é o início da terceira fase, chamada de integração, em que é marcada pela visão de que a pessoa com deficiência poderia conviver em sociedade, se beneficiar da sociabilidade com todos e não somente com certas pessoas em ambientes específicos, desde que elas se adaptassem ao meio.

É visível que as pessoas com deficiência trazem consigo anos de perseguição e preconceito, os quais se propagavam em decorrência de um fator cognitivo, auditivo, visual dentre outros. Por causa dessa intolerância, tais pessoas eram proibidas de casar, comprar/alugar/vender um imóvel, escolher sua profissão, fazer um testamento, ou seja, até o próprio legislador limitava seus direitos. Havia contrariedade, dessa forma, a uns dos pilares da democracia e princípio constitucional, a saber, a igualdade material, prevista na forma do art. 50, caput da Constituição Federal. ${ }^{?}$

\footnotetext{
${ }^{7}$ Art. $5^{0}$ Todos são iguais perante a lei, sem distinção de qualquer natureza, garantindo-se aos brasileiros e aos estrangeiros residentes no País a inviolabilidade do direito à vida, à liberdade, à igualdade, à segurança e à propriedade, nos termos seguintes. (BRASIL, 1988).
} 
Cabe salientar as mudanças ocorridas na década de 30 do século XX como, por exemplo, o implemento do Decreto $n^{\circ} 891 / 38^{8}$ e a revogação do Decreto $n^{\circ}$ $24.559 / 34^{9}$ pelo Decreto $n^{\circ} 99.678 / 90 .^{10}$ Visto que, o Decreto $n^{\circ} 891 / 38$ trouxe à tona o regulamento e fiscalização de entorpecentes, ou seja, dispôs sobre questões relativas à produção, ao tráfico e ao consumo, proibindo, dessa forma, inúmeras substâncias consideradas entorpecentes e, por conseguinte, a interdição dos toxicômanos, levando em consideração o grau de intoxicação e prejuízo causado à sua consciência e ao seu discernimento. Nesse sentido, a interdição poderia ser plena ou limitada, equiparando o interdito ao absolutamente incapaz ou relativamente incapaz, respectivamente ${ }^{11}$. Assim, uma das principais mudanças oriundas da Lei 13.146/2015 (BRASIL, 2015a) foi promover a alteração da redação do art. $4^{\circ}$ do Código Civil, ao prever como, relativamente incapaz, os ébrios habituais e os viciados em tóxico, uma vez que, segundo a lei, não há afetação das liberdades pessoais por déficit cognitivo.

O Decreto $n^{\circ} 24.559 / 34$ foi o primeiro aparato legal voltado à pessoa com transtorno mental que fez menção ao ser humano que, ao dispor sobre a assistência e proteção individual, bem como sobre os bens dos psicopatas, considerava loucos os anormais, os toxicômanos, os intoxicados habituais e os indivíduos suspeitos incapazes de exercer pessoalmente os atos da vida civil (BRASIL, 1934). No mais, tal Decreto substituiu a expressão "loucos de todo o gênero" pelo termo "psicopatas", por ser considerado cientificamente mais adequado, sendo assim todo aquele "portador de psicopatologia, ou seja, portador de qualquer moléstia mental, de qualquer anomalia ou de qualquer etiologia." (GAMA, 2008, p. 608). No processo de interdição da pessoa considerada psicopata, o Decreto n 24.559/34 permitia que

\footnotetext{
${ }^{8}$ (BRASIL, 1938).

${ }^{9}$ (BRASIL, 1934).

${ }^{10}$ (BRASIL, 1990).

${ }^{11}$ Decreto-Lei no 891/1938: Art. 30. A simples internação para tratamento bem como interdição plena ou limitada serão decretadas por decisão judicial, pelo tempo que os peritos julgarem conveniente segundo o estado mental do internado.

$\S 1^{0}$ Será decretada em procedimento judicial e secreto a simples internação para tratamento, si o exame pericial não demonstrar necessidade de limitação de capacidade civil do internado.

$\S 5^{\circ} \mathrm{A}$ internação limitada importa na equiparação do interdito aos relativamente incapazes, assim como a interdição plena o equipara aos absolutamente incapazes, respectivamente na forma dos artigos $6^{\circ}$ e $5^{\circ}$ do Código Civil. (BRASIL, 1938).
} 
fosse declarada a incapacidade absoluta ou relativa do interdito, conforme a gravidade do comprometimento psíquico. ${ }^{12}$

Sob esse aspecto, o Código Civil de 1916, sob uma forte influência do modelo médico, enquadrou as pessoas com transtorno mental como "loucos de todo o gênero" e, conseguintemente, como absolutamente incapazes. Observa-se que o Código Civil de 2002, antes da Lei $n^{\circ} 13.146 / 2015$, seguiu a mesma metodologia que o Código anterior ao enquadrar as pessoas com transtorno mental como incapazes, mesmo que elas possuíssem um mínimo de discernimento. Sem embargo, com o advento da Lei $13.146 / 2015$ as pessoas com transtorno mental foram retiradas do rol de absolutamente incapazes, visto que o escopo de referida lei é que deficiência não induz a incapacidade.

Assim, por 86 (oitenta e seis) anos o Código Beviláqua (Código Civil de 1916) esteve vigente até que foi revogado pela Lei 10.406/02 (Código Civil de 2002). Com a chegada deste, o regime das incapacidades sofreu alterações, sendo suscitadas mudanças em relação ao seu conteúdo e ao modo de aferição de determinados incapazes, principalmente, no que tange às pessoas com deficiência.

A Lei 10.406/02 estabeleceu, portanto, que a proteção aos relativamente ou absolutamente incapazes dar-se-ia em face do grau de discernimento ou de necessidade da pessoa e não mais critérios objetivos e taxativos.

\section{REGIME DAS INCAPACIDADES DE 2002}

Nos primeiros 13 (treze) anos de vigência do Código Civil de 2002, conservou-se parte da redação dos revogados dispositivos do Código Civil de 1916, havendo, tão somente, a retirada dos "surdos-mudos" (artigo 5, III Código Civil de 1916) e dos "ausentes, declarados tais por ato do juiz" (artigo 5, IV Código Civil de 1916). Notou-se que as deficiências sensoriais, embora possam prejudicar, em termos práticos, o pleno gozo das capacidades individuais, nunca foram na lei motivo de atribuição da incapacidade civil; além disso, essas deficiências não impediam essas pessoas de exprimirem sua vontade. Portanto, evidencia-se que não há

${ }^{12}$ Decreto no 24.559/1934: Art. 26. Os Psicopatas, assim declarados por perícia médica processada em forma regular, são absoluta ou relativamente incapazes de exercer pessoalmente os atos da vida civil. (BRASIL, 1934). 
nenhuma afetação das liberdades do discernimento em razão de uma deficiência sensorial.

A doutrina entendia na época que as pessoas com deficiência mental estavam inseridas no inciso II do art. 50, do Código Civil de 1916 - "os que, por enfermidade ou deficiência mental, não tiverem o necessário discernimento para a prática desses atos. ", visto que o pensamento genérico empregado pelo legislador pátrio incorporaria, na lição de Carlos Roberto Gonçalves:

Todos os casos de insanidade mental, provocada por doença ou enfermidade mental congênita ou adquirida, como a oligofrenia e a esquizofrenia, por exemplo, bem como por deficiência mental decorrente de distúrbios psíquicos, desde que em grau suficiente para acarretar a privação do necessário discernimento para a prática dos atos da vida civil. (GONÇALVES, 2013, p. 113).

Daí entende-se que a absoluta incapacidade não decorria meramente da existência de uma patologia clínica, mas somente quando houvesse a perda do discernimento necessário para a prática dos atos da vida civil. Outrossim, as pessoas com deficiência não eram consideradas necessariamente incapazes, uma vez que essa aferição dependia de uma avaliação judicial prévia.

Percebe-se que os deficientes mentais foram considerados incapazes. Todavia, o raciocínio mudou com a aprovação do EPD, ao assegurar, em seu art. $6^{\circ 13}$, que o fato de uma pessoa apresentar uma deficiência não afeta sua plena capacidade civil. Verificou-se, ainda assim, que com a redução mesmo que ínfima do discernimento, a pessoa com deficiência é capaz de manifestar sua vontade e, além do mais, essa pessoa não precisa vir acompanhada de um curador ou outro representante para praticar atos simples da vida civil como, por exemplo, a compra de um imóvel, salvo se for de escolha do deficiente.

A Lei 13.146/2015, portanto, veio com o objetivo de incluir as pessoas com deficiência na legislação civilista, uma vez que essa, por anos, os excluía da

\footnotetext{
${ }^{13}$ Art. $6^{0}$ A deficiência não afeta a plena capacidade civil da pessoa, inclusive para: I - casar-se e constituir união estável; II - exercer direitos sexuais e reprodutivos; III - exercer o direito de decidir sobre o número de filhos e de ter acesso a informações adequadas sobre reprodução e planejamento familiar; IV - conservar sua fertilidade, sendo vedada a esterilização compulsória; V - exercer o direito à família e à convivência familiar e comunitária; e VI - exercer o direito à guarda, à tutela, à curatela e à adoção, como adotante ou adotando, em igualdade de oportunidades com as demais pessoas. (BRASIL, 2015a).
} 
sociedade e os tratavam como doentes. Ademais, essa Lei trouxe significantes mudanças nos institutos do Direito Civil, entre os quais o regime das incapacidades, a prescrição, a curatela, verificando-se alterações e revogações de normas positivadas em lei a respeito desses institutos.

\section{REGIME DAS INCAPACIDADES NO EPD}

A Lei 13.146/2015, mais conhecida como Estatuto da Pessoa com Deficiência, ou Lei Brasileira de Inclusão da Pessoa com Deficiência, trouxe importantes avanços para a promoção da igualdade formal e material das pessoas com deficiência no Brasil.

O Estatuto é baseado nos princípios e regras da Convenção Internacional sobre os Direitos das Pessoas com Deficiência e seu Protocolo Facultativo, também conhecida como Convenção de Nova Iorque, que foi introduzida no ordenamento jurídico brasileiro através do Decreto no 6.949, de 25 de agosto de 2009 (BRASIL, 2009). Trata-se do único tratado internacional ratificado pelo Brasil com status de emenda constitucional, nos termos do artigo $5^{\circ}, \S 30$, da Constituição da República de 1988 (BRASIL, 1988).

O principal objetivo desse Estatuto é assegurar e promover, em condições de igualdade, o exercício dos direitos e das liberdades fundamentais por pessoa com deficiência, visando à sua inclusão social e cidadania. Dessa forma, o Estatuto objetiva tratar o deficiente como plenamente capaz, até que se prove o contrário. Assim, a sociedade que deve se adaptar a deficiência e não o contrário.

Essa mudança é oriunda do novo conceito mundial de deficiência, em que se afasta o modelo médico para aceitar o modelo social: deficiente é aquele que tem dificuldade de se integrar à sociedade, conforme dito 0 art. $2^{\circ}$ do Estatuto:

Considera-se pessoa com deficiência aquela que tem impedimento de longo prazo de natureza física, mental, intelectual ou sensorial, o qual, em intervenção com uma ou mais barreiras, pode obstruir sua participação plena e afetiva na sociedade em igualdade de condições com as demais pessoas. (BRASIL, 2015a, não paginado)

Nesse sentido, o EPD, ao declarar a capacidade da pessoa com deficiência redefiniu a tradicional teoria civilista da incapacidade, tanto que alguns dispositivos 
do $\mathrm{CC} / 2002$ foram revogados e outros tiveram seus textos modificados. Como visto, os três incisos do art. $3^{\circ}$ do Código Civil foram revogados e o absolutamente incapaz é unicamente o menor de dezesseis anos. Já o art. 4ºdo Código Civil, que diz respeito aos relativamente incapazes, é composto por dois incisos e neles constam os ébrios habituais, os viciados em tóxicos, além daqueles que, por causa transitória ou permanente, não puderem exprimir sua vontade. Assim, a principal mudança promovida pelo Estatuto é garantir uma presunção geral de plena capacidade a favor das pessoas com deficiência, tal como se verifica em relação a qualquer outra pessoa.

Considerando tais colocações supramencionadas, é pertinente vislumbrar uma segunda mudança trazida pelo Estatuto: as pessoas com deficiência mental passam a ter plena capacidade, podendo inclusive casar, constituir união estável e exercer guarda e tutela de outrem, como afirmado explicitamente no art. $6^{\circ}$ da Lei 13.146/2015 (BRASIL, 2015a) ${ }^{14}$. Essa vicissitude é de grande repercussão na doutrina civilista brasileira, uma vez que outrora esses direitos civis eram negados às pessoas com deficiência, em razão de uma alegação subjetivista que essas pessoas, por não conseguirem expressar seu discernimento por completo, não estariam aptas a praticar os atos mais triviais da vida civil.

Outro ponto a salientar é que essas pessoas são dotadas de plena capacidade jurídica, em igualdade de condições com as demais pessoas ${ }^{15}$, pois "uma deficiência não induz necessariamente à incapacidade" (FARIAS; ROSENVALD, 2016, p. 326) e "nem toda pessoa incapaz juridicamente é, necessariamente, deficiente" (FARIAS; ROSENVALD, 2016, p. 329) como, por exemplo, uma pessoa em estado comatoso ou estado hipnótico que, apesar, de não conseguir manifestar sua vontade, não é mais considerada absolutamente incapaz e, sim relativamente incapaz, sendo designado um curador a ela. Além do mais, com o advento do EPD

\footnotetext{
${ }^{14} \mathrm{Art} .6^{\circ} \mathrm{A}$ deficiência não afeta a plena capacidade civil da pessoa, inclusive para:

I - casar-se e constituir união estável;

II - exercer direitos sexuais e reprodutivos;

III - exercer o direito de decidir sobre o número de filhos e de ter acesso a informações adequadas sobre reprodução e planejamento familiar;

IV - conservar sua fertilidade, sendo vedada a esterilização compulsória;

V - exercer o direito à família e à convivência familiar e comunitária; e

VI - exercer o direito à guarda, à tutela, à curatela e à adoção, como adotante ou adotando, em igualdade de oportunidades com as demais pessoas. (BRASIL, 2015a).

${ }^{15}$ Art. 84, da Lei 13.146/2015. (BRASIL, 2015a).
} 
retira-se a ideia de discernimento como fator qualificativo de incapacidade civil, visto que o legislador ao utilizar desse termo trazia consigo uma abordagem discriminatória e excludente às pessoas com deficiência, principalmente, às pessoas com deficiência mental ou intelectual. Em suma, assevera Bruna Lima de Mendonça: "Não há mais qualquer presunção da incapacidade das pessoas com deficiência por ausência de discernimento." (BARBOZA; MENDONÇA; ALMEIDA JUNIOR, 2017, p. 43).

Por outro lado, há autores que, não satisfeitos com os novos horizontes trazidos pelo EPD, são favoráveis à mudança na redação da lei como, por exemplo, o autor Waldir Macieira da Costa Filho ${ }^{16}$. Tal posição tem como fundamento a questão de se o EPD colocaria as pessoas com deficiência em uma situação de vulnerabilidade, ao retirá-las do rol dos incapazes. Tal se justificaria, segundo o Projeto de Lei do Senado no 757/2015 ${ }^{17}$ dos Senadores Antônio Carlos Valadares e Paulo Paim pois, o EPD, na tentativa de empoderar e respeitar as pessoas com deficiência, as desprotegeu, deixando-as mercê da própria sorte ao executar os atos da vida civil. Sob esse prisma, tal projeto de lei citado anteriormente, traz consigo a ideia de alterar os artigos $3^{\circ}$ e $4^{18}$ do Código Civil de 2002 com a inclusão de novos incisos em sua redação.

No entanto, tal proposta de modificação, ao meu ver, é polêmica, já que, por se tratar de norma restritiva de direitos, deve ser interpretada sempre stricti iures, ou seja, as hipóteses que ensejam a incapacidade absoluta ou relativa são sempre aquelas previstas em lei, com caráter de ordem pública, pois toda incapacidade é legal. No mais, trata-se, também, de proposta que vai na contramão dos artigos $6^{\circ} \mathrm{e}$

${ }^{16} \mathrm{O}$ autor participou das primeiras discussões sobre o substitutivo ao PLS 757/2015 no Senado e afirmou que tal projeto de lei resguardará a finalidade da LBI relativo a garantia da capacidade legal das pessoas com deficiências como um todo de maneira geral. (COSTA FILHO, 2016).

${ }^{17}$ (BRASIL, 2015b).

${ }^{18}$ No Código Civil:

Art. $3^{\circ}$ São absolutamente incapazes de exercer pessoalmente os atos da vida civil: [...]

IV - os menores de dezesseis anos;

V - os que não tenham qualquer discernimento para a prática desses atos, conforme decisão judicial que leve em conta a avaliação biopscossocial;

VI - os que, mesmo por causa transitória, não puderem exprimir sua vontade.

Art. 40

II - os ébrios habituais, os viciados em tóxicos e os que tenham o discernimento reduzido de forma relevante, conforme decisão judicial que leve em conta a avaliação bispsocossocial; [...] (BRASIL, 2002). 
114 do EPD. Assim, ainda que a pessoa apresente uma deficiência mental ou intelectual grave, será presumida a sua plena capacidade, pois a regra do ordenamento jurídico, mediante a nova sistemática do regime das incapacidades, é a plena capacidade. Ademais, vale ressaltar outra manifestação contra legem aos artigos $6^{\circ}$ e 114do EPD, exteriorizada na reunião de trabalho realizada em 26/02/2016, em Brasília -DF, pelos membros do Ministério Público e do Distrito Federal e Territórios (MPDFT) com o intuito de aprovar alguns enunciados ${ }^{19}$, principalmente, o quarto. Esse versa acerca, nos casos necessários, da decretação de incapacidade absoluta das pessoas com deficiência. Ou seja, evidencia-se o regresso por parte de certos autores, ao voltar com a ideia, já extinta, da presunção de discernimento para a decretação de incapacidade.

Além de Waldir Macieira da Costa Filho, outros autores afirmam que o diploma legislativo desprotegeu as pessoas com deficiência ao retirá-las do rol dos incapazes. Dentre os que adotam essa posição, é possível citar José Fernando Simão (2015) e Vitor Kümpel (2015). De outro lado, há autores que aclamaram as recentes alterações como Joyceane Bezerra, Paulo Lôbo (2009), Pablo Stolze (2016), Flávio Tartuce (2015) e Nelson Rosenvald. Desse modo, o Estatuto preconiza como ideia fulcral que a capacidade é regra, incapacidade é exceção.

Cabe salientar que umas das principais mudanças oriundas da Lei 13.146/2015 foi a mudança na nomenclatura de "pessoa portadora de deficiência" para "pessoa com deficiência". Uma vez que, a deficiência não é um objeto para ser portado e, sim, algo inerente e intrínseco do ser humano como, por exemplo, a cor da pele. O uso da nomenclatura "pessoa portadora de deficiência" ou "pessoa

\footnotetext{
19 "Primeiro enunciado: A Lei 13.146/2015 não alcança as interdições já decretadas por sentença com trânsito em julgado, sem prejuízo da possibilidade de o interessado requerer, a qualquer tempo, nos próprios autos da interdição, a revisão dos limites da curatela e a substituição da interdição pela tomada de decisão apoiada, conforme o caso.

"Segundo enunciado: Nos procedimentos de curatela ou de tomada de decisão apoiada, o juiz não é obrigado a observar critério de legalidade estrita, podendo adotar em cada caso a solução que considerar mais conveniente ou oportuna, conforme dispõe o art. 723, parágrafo único, do novo CPC (Lei 13.105/2015). .

"Terceiro enunciado: $O$ art. 85 da Lei 13.146/2015 deve ser interpretado em consonância com o art. 723, parágrafo único, do novo $\mathrm{CPC}$, de forma que a curatela da pessoa com deficiência poderá afetar o exercício de direitos de natureza extrapatrimonial, desde que essa restrição conste da sentença.

"Quarto enunciado: Os arts. $3^{\circ}$ e $4^{\circ}$ do Código Civil, com a nova redação dada pela Lei 13.146/2015, não disciplinam todas as hipóteses de incapacidade, de forma que poderá ser decretada por sentença a incapacidade absoluta da pessoa com deficiência, nos casos em que houver necessidade." (BRASIL, 2015a)
} 
especial" ou "pessoa incapaz" carrega consigo um forte peso da exclusão social e da interiorização. Dessa forma, a Convenção da ONU sobre Direitos da Pessoa com Deficiência adotou a expressão "pessoa com deficiência".

O Estatuto da Pessoa com Deficiência procura a integração e, mais do que isso, a inclusão das pessoas portadoras de deficiência na sociedade. Através da integração buscou-se o fim da prática de exclusão social que atingiu durante séculos as pessoas com deficiência. Ou seja, essas pessoas eram banidas de qualquer atividade social por serem consideradas inválidas e incapazes de trabalhar, sendo considerados sem utilidade para a sociedade. Dessa forma, era necessário criar condições de vida para que a pessoa com deficiência se adequasse às condições normais da sociedade em que vive.

Evidencia-se que o Estatuto tem como núcleo central a premissa que a pessoa com deficiência é igual a qualquer outra pessoa, visto que ela passa a ter capacidade plena, conforme apregoado por Elisa Costa Cruz (2017, p. 78): "não há, segundo a lei, afetação das liberdades pessoais por déficit cognitivo. Isto quer dizer, que a deficiência não gera qualquer problema quanto ao tema da capacidade. Nesse sentido, toda pessoa com deficiência, seja de ordem mental, intelectual ou qualquer natureza, é plenamente capaz de exercer os atos da vida civil e tem o direito à igualdade de oportunidades com as demais pessoas, além de não poder sofrer qualquer espécie de descriminação, art. $4^{\circ}$ do EPD (BRASIL, 2015a).

Ademais, esse ato normativo preconiza que a deficiência não é mais considerada uma barreira ou obstáculo para as pessoas com deficiência e, sim, algo inerente e normal de suas vidas como, por exemplo, a orientação sexual. Outrossim, com o advento do EPD, suprimiu-se o modelo médico ou "modelo reabilitador", proveniente do Código Civil de 1916, o qual difundia que a exclusão e descriminalização sofrida por essas pessoas era oriunda delas mesmas, ou seja, encarava a deficiência como condição patológica de natureza individual, trouxe a ideia de que a deficiência está, tão somente, na sociedade e esta deve se adaptar às pessoas com deficiência, bem como, o Direito.

Em contrapartida, o EPD, apesar de ser promissor no que tange ao regime da capacidade e dos direitos fundamentais às pessoas com deficiência, repercutiu negativamente em outros institutos do Direito Civil como, por exemplo, a 
responsabilidade. Uma vez que, outrora, para as pessoas com deficiência a responsabilidade detinha um caráter subsidiário, isto é, tal como previsto no art. 928 do Código Civil de $2002^{20}$ o incapaz só responderia se o seu responsável não tivesse obrigação de suportar tal dever de reparação ou não dispusesse de meios suficientes. No entanto, a pessoa com deficiência por não fazer mais parte dos absolutamente incapazes, perde essa importante proteção e, ao ser deslocado dessa regra, passando a responder com os seus bens pelos seus atos. Ademais, outro instituto modificado foi o da prescrição e da decadência, isto quer dizer, tanto os prazos prescricionais quanto os prazos decadenciais correrão normalmente contra eles, pois a proteção, consoante os arts. 198 , I ${ }^{21}$, e $208^{22}$ do Código Civil de 2002, é dirigida aos absolutamente incapazes.

O EPD ao atribuir às pessoas com deficiências a plena capacidade civil, em verdade, intenta erradicar o preconceito e promover a inclusão social, com o intuito de evitar ao máximo o afastamento do deficiente com o meio ao qual ele está inserido. Nesse aspecto, o EPD, portanto, reconfigurou todo o sistema civilista, pois o mesmo criou alguns institutos como a curatela de capazes e a tomada de decisão apoiada, ao passo que outros não existirão mais, como a curatela de absolutamente incapaz, a nulidade do casamento em face de enfermos mentais.

\section{CONSIDERAÇÕES FINAIS}

O presente estudo pretendeu, à luz das balizas metodológicas do Direito Civil- Constitucional, apresentar as etapas do regime das incapacidades em cada Código Civil brasileiro e com o advento do Estatuto da Pessoa com Deficiência, buscando o foco nas alterações e mudanças dos artigos, trazer uma visão acerca da conjuntura de cada época e como a doutrina enxergou cada modificação.

Com esta proposta, objetiva-se analisar o Estatuto da Pessoa com Deficiência sob o enfoque da sociedade civil, uma vez que muitos doutrinadores asseveram que

\footnotetext{
${ }^{20}$ Art. 928. O incapaz responde pelos prejuízos que causar, se as pessoas por ele responsáveis não tiverem obrigação de fazê-lo ou não dispuserem de meios suficientes (BRASIL, 2002).

${ }^{21}$ Art. 198. Também não corre a prescrição: I - contra os incapazes de que trata 0 art. $3^{\circ}$ (BRASIL, 2002).

${ }^{22}$ Art. 208. Aplica-se à decadência o disposto nos arts. 195 e 198, inciso I (BRASIL, 2002).
} 
esse Estatuto, na teoria, é muito promissor, enquanto outros dizem o contrário, já que, na prática, não condiz às normas propostas pelo próprio Estatuto. Desse modo, - legislador deve garantir e prever "pequenos" direitos como, por exemplo, construção de rampas, colocação de pisos táteis, instalação de avisos sonoros; a "amplos" direitos como, por exemplo, constituição de uma sociedade empresária, participação de uma sociedade empresária com o intuito de criar, não apenas uma disfarçada integração, mas, sim, uma robusta inclusão dessas pessoas na sociedade hodiernamente.

Todo o conjunto das alterações e novidades trazidas com a Convenção de Nova Iorque sobre os Direitos das Pessoas com Deficiência e, posteriormente, com o advento do Estatuto da Pessoa com Deficiência, veio a buscar dar maior consideração e respeito às pessoas com deficiência na perspectiva da implementação efetiva dos seus direitos humanos e fundamentais, em especial a liberdade, a segurança, a igualdade material, a integridade físico-psíquica e a vida digna. Sob esse prisma deve-se analisar e compreender o novo modelo do regime das incapacidades no Direito Civil brasileiro que se associa e se fundamenta no valor e princípio fundamental do ordenamento jurídico brasileiro, a saber, a dignidade da pessoa humana, aí também compreendida a pessoa com deficiência.

\section{REFERÊNCIAS}

BARBERO, Domenico. Sistema istituzionale del diritto privato italiano. Torino: Torinese, 1950. v. 1.

BARBOZA, Heloísa Helena; MENDONÇA, Bruna Lima de; ALMEIDA JUNIOR, Vitor de Azevedo. O Código Civil e o Estatuto da Pessoa com Deficiência. Rio de Janeiro: Processo, 2017.

BODIN DE MORAES, Maria Celina. Na medida da pessoa humana: estudos de direito civil-constitucional. Rio de Janeiro: Renovar, 2010.

BRASIL. [Constituição (1988)]. Constituição da República Federativa do Brasil de 1988. Brasília, DF: Presidência da República, [2016]. Disponível em: http://www.planalto.gov.br/ccivil_03/Constituicao/Constituiçao.htm. Acesso em: 06 fev. 2019.

BRASIL. Decreto $\mathbf{n}^{0} \mathbf{2 4 . 5 5 9}$, de 3 de julho de 1934. Dispõe sobre a profilaxia mental, a assistência e proteção à pessoa e aos bens dos psicopatas, a fiscalização 
dos serviços psiquiátricos e dá outras providências. Rio de Janeiro: Presidência da República, 1934. Disponível em: http://www.planalto.gov.br/ccivil_03/decreto/19301949/D24559.htm. Acesso em: 26 nov. 2018.

BRASIL. Decreto no 891, de 25 de novembro de 1938. Aprova a Lei de Fiscalização de Entorpecentes. Rio de Janeiro: Presidência da República, 1934. Disponível em: http://www.planalto.gov.br/ccivil_03/decreto-lei/19371946/Del0891.htm. Acesso em: 26 nov. 2018.

BRASIL. Decreto no 99.678, de 8 de novembro de 1990. Aprova a Estrutura Regimental do Ministério da Educação e dá outras providências. Brasília, DF: Presidência da República, 1990. Disponível em: http://www.planalto.gov.br/ccivil_03/decreto/Antigos/D99678.htm\#art4. Acesso em: 26 nov. 2018.

BRASIL. Decreto no 6.949, de 25 de agosto de 2009. Promulga a Convenção Internacional sobre os Direitos das Pessoas com Deficiência e seu Protocolo Facultativo, assinados em Nova York, em 30 de março de 2007. Brasília, DF: Presidência da República, 2009. Disponível em: http://www.planalto.gov.br/ccivil_03/_ato2007-2010/2009/decreto/d6949.htm. Acesso em: 26 nov. 2018.

BRASIL. Lei $\mathbf{n}^{\mathbf{0}} \mathbf{3 . 0 7 1}$, de $1^{\circ}$ de janeiro de 1916. Código Civil dos Estados Unidos do Brasil. Rio de Janeiro: Presidência da República, 1916. Disponível em: http://www.planalto.gov.br/ccivil_03/leis/L3071.htm. Acesso em: fev. 2019.

BRASIL. Lei no 10.406, de 10 de janeiro de 2002. Institui o Código Civil. Brasília, DF: Presidência da República, 2002. Disponível em: http://www.planalto.gov.br/ccivil_03/leis/2002/l10406.htm. Acesso em: 24 nov. 2018.

BRASIL. Lei no 13.146, de 6 de julho de 2015. Institui a Lei Brasileira de Inclusão da Pessoa com Deficiência (Estatuto da Pessoa com Deficiência). Brasília, DF: Presidência da República, 2015a. Disponível em: http://www.planalto.gov.br/ccivil_03/_Ato2015-2018/2015/Lei/L13146.htm. Acesso em: 06 fev. 2019.

BRASIL. Senado Federal. Projeto de lei do Senado n⿳0 757, de 2015. Altera a Lei no 10.406, de 20 de janeiro de 2002 (Código Civil), a Lei no 13.146, de 16 de março de 2015 (Estatuto da Pessoa com Deficiência), e a Lei no 13.105, de 16 de março de 2015 (Código de Processo Civil), para dispor sobre a igualdade civil e o apoio às pessoas sem pleno discernimento ou que não puderem exprimir sua vontade, os limites da curatela, os efeitos e o procedimento da tomada de decisão apoiada. Brasília, DF: Senado Federal, 2015b. Disponível em: https://www25.senado.leg.br/web/atividade/materias/-/materia/124251. Acesso em: 06 fev. 2019. 
CASTRO MENDES, João de. Direito Civil. Teoria Geral. Lisboa: Associação Acadêmica da Faculdade de Direito, 1979.

CATALANO, Pierangelo. Osservazioni sulla "persona" dei nascituri alla luce del Diritto Romano (Da Giuliano a Teixeira de Freitas). In: CATALANO, Pierangelo. Diritto e persone. Turim: Giappichelli, 1990. p. 202-204.

CRUZ, Elisa Costa. A Parte Geral do Código Civil e a Lei Brasileira de Inclusão. In: BARBOZA, Heloisa Helena; MENDONÇA, Bruna Lima de; ALMEIDA JUNIOR, Vitor de Azevedo (Coord.). 0 Código Civil e o Estatuto da Pessoa com Deficiência. Rio de Janeiro: Processo, 2017. p. 67-98.

FARIAS, Cristiano Chaves; ROSENVALD, Nelson. Curso de Direito civil: parte geral e LINDB. 14. ed. rev., ampl. E atual. Salvador: Ed. JusPodivm, 2016.

COSTA FILHO, Waldir Macieira da. Reflexões sobre a Lei 13.146: a Concepção de deficiência e capacidade civil. E os institutos da curatela e tomada de decisão apoiada. Revista do Ministério Público do Estado do Pará, Pará, v. 9, n. 9, 2016.

GAMA, Guilherme Calmon Nogueira da. Direito civil: parte geral, v. 1. São Paulo: Atlas, 2006.

GAMA, Guilherme Calmon Nogueira da. Direito civil: família. São Paulo: Atlas, 2008. GONÇALVES, Carlos Roberto. Direito civil brasileiro: parte geral. 11. ed. São Paulo: Saraiva, 2013. v. 1.

KÜMPEL, Vitor Frederico; BORGARELLI, Bruno de Ávila. A lei 13.146/2015 e a atuação de notários e registradores diante dos deficientes. Disponível em: http://www.possiedearaujo.com.br/\#!A-lei-131462015-e-a-atua\%C3\%A7\%C3\%A3ode-not\%C3\%A1rios-e-registradores-diante-dosdeficientes/c1rh7/55d748470cf2174523e337b7.Acesso em: 06 fev. 2019.

LÔBO, Paulo. Direito Civil: parte geral. São Paulo: Saraiva, 2009.

MEDEIROS, Marcelo; DINIZ, Débora. A nova maneira de se entender a deficiência e o envelhecimento. Brasília: IPEA, 2004. Disponível em: http://www.ipea.gov.br/portal/images/stories/PDFs/TDs/td_1040.pdf. Acesso em: 26 nov. 2018.

MONTEIRO, Washington de Barros. Curso de direito civil: parte geral. 39. ed. rev. e atual. por Ana Cristina de Barros Monteiro França Pinto. São Paulo: Saraiva, 2003. v. 1.

MOTA PINTO, Carlos Alberto da. Teoria Geral do Direito Civil. 4. ed. Por António Pinto Monteiro e Paulo Mota Pinto. Coimbra: Coimbra Editora, 2005. 
PEREIRA, Caio Mário da Silva. Instituições de Direito Civil. rev. e atual. Rio de Janeiro: Forense, 2018. v. 1.

RODRIGUES, Rafael Garcia. A pessoa e o ser humano no novo Código Civil. In: TEPEDINO, Gustavo (coord.). A parte geral do novo Código Civil: estudos na perspectiva civil-constitucional. 2. ed. rev. e atual. Rio de Janeiro: Renovar, 2003.

SIMÃO, José Fernando. Estatuto da Pessoa com Deficiência causa perplexidade (Parte I). Consultório Jurídico, [S.I.], 6 ago. 2015. Disponível em: https://www.conjur.com.br/2015-ago-06/jose-simao-estatuto-pessoa-deficienciacausa-perplexidade. Acesso em: 06 fev. 2019.

STOLZE, Pablo. Deficiência não é causa de incapacidade relativa: a brecha autofágica. Revista Jus Navigandi, Teresina, v. 21, n. 4794, 16 ago. 2016. Disponível em: https://jus.com.br/artigos/51407/deficiencia-nao-e-causa-deincapacidade-relativa. Acesso em: 06 fev. 2019.

TARTUCE, Flávio. Alterações do Código Civil pela lei 13.146/2015 (Estatuto da Pessoa com Deficiência). Repercussões para o Direito de Família e Confrontações com o Novo CPC. Parte II. Migualhas, Famílias e sucessões. [S.I.], 29 jul. 2015. Disponível em: https://www.migalhas.com.br/FamiliaeSucessoes/104,MI224217,21048Alteracoes+do+Codigo+Civil+pela+lei+131462015+Estatuto+da+Pessoa+com. Acesso em: 06 fev. 2019. 